The house of delegates of the Academy of Nutrition and Dietetics recently selected research engagement as a mega-issue because research is critical to showing the value of the registered dietitian nutritionist's (RDN's) services, but many RDNs do not consider research as part of their role or believe they lack the skills to participate. ${ }^{1}$ Dietetics Practice Based Research Network (DPBRN) projects have provided evidence to support RDN services in containing costs and improving patient outcomes. ${ }^{2}$ Engaging a diverse array of members in a culture of research is particularly relevant given the recent House of Delegates mega-issue. After identifying human subjects protection training (defined and described later) as a barrier to research participation, the Academy's DPBRN developed and pilot-tested a research ethics course specific for RDNs. This article describes the development and pilottesting of this course as well as next steps for all Academy members to use this resource.

In a 2002 survey of RDNs, only $27 \%$ of respondents had participated in research. ${ }^{3}$ The most frequently selected barrier to conducting research was not having research skills (65\% of those who had not conducted research), followed by lack of time or staff (41\% of those who had not conducted research). ${ }^{3}$ However, RDNs consistently believe that research is important to the profession and many would like to participate. ${ }^{4}$ This is not unique to the dietetics profession; previous studies have shown a lack of participation in research by health care providers not associated with academic institutions, such as a practicing RDN. One barrier to participating in research is the requirement for human subjects protection

Copyright $\odot 2014$ by the Academy of Nutrition and Dietetics.

STATEMENT OF POTENTIAL CONFLICT OF INTEREST

No potential conflict of interest was reported by the authors.

Its contents are solely the responsibility of the authors and do not necessarily represent the official views of the NIH. 
training. To overcome this barrier, the Academy worked with research ethics experts to create a human subjects protection training specific to nutrition and dietetics.

Protection of human subjects in research is a key concern of both investigators and research regulators such as the institutional review boards (IRBs). IRBs must ensure that all individuals listed as key personnel on funded National Institutes of Health grants are educated in the protection of human subjects. ${ }^{5}$ To address this need, most institutions (or their IRBs) require a human subjects protection training course for all researchers who interface with human subjects or their data. ${ }^{6}$ The majority of these courses are based on the assumed needs of academic researchers and require a baseline level of research knowledge for comprehension. ${ }^{6}$ Given the traditional target audience of these training programs, nonacademic researchers frequently perceive the content as not relevant or inaccessible. These programs may not fulfill the needs of nontraditional researchers such as clinicians and community partners regarding the type of ethical dilemmas or concerns that arise outside the traditional academic research context. ${ }^{6}$ For example, clinicians who are also acting as researchers, including RDNs, may serve multiple roles (clinician and researcher) in relation to a single patient/subject. These dual roles usually have different priorities, and the difference may not be obvious to patients, which can affect the ethics of recruiting and obtaining informed consent. ${ }^{7}$

Community-based participatory research (CBPR) has also encountered the challenge of making training in human subjects protection relevant to nontraditional researchers. To overcome these barriers and ensure that community researchers have the training needed to conduct studies ethically, some institutions have developed alternative human subjects protection trainings to meet the needs of community researchers. ${ }^{6}$ Examples include the CIRTification (Community Involvement in Research Training) from the University of Illinois at Chicago, the Field Training Guide for Human Subjects Research Ethics from Johns Hopkins University, and Protecting People Who Participate in Research from the University of North Carolina-Chapel Hill. ${ }^{6}$

Given that a baseline knowledge of research terminology and regulations (such as how research is defined and the differences between research and standard clinical care) is assumed in many of the existing human subjects protection training courses, ${ }^{6}$ lack of research knowledge and skills adds another level of difficulty to completing the course. Thirty-one percent of RDNs surveyed in 2000 indicated that their preferred route to research knowledge was through training tailored to clinical dietitians, ${ }^{8}$ showing that RDNs are more interested in research when concepts are specific to them. The need for the learner to perceive applicability to be interested in a topic is not unique to RDNs; the study of adult education emphasizes the importance of the learner's internal motivation, past experience, and perceived utility/applicability of the lesson. ${ }^{9}$

To provide external as well as internal motivators, a direct benefit (such as continuing professional education [CPE] credits) may provide an incentive for professionals to find time in their schedules to complete the training. Annual surveys of Academy of Nutrition and Dietetics' membership show that obtaining CPE credits is very important to most individuals (Academy of Nutrition and Dietetics Research Committee, unpublished data, 
2013). In a separate recent survey of the Academy membership, $69 \%$ of respondents reported that regulatory requirements such as human subjects protection training were a barrier to their participation in research. ${ }^{10}$ One of the courses frequently required by academic institutions to fulfill their Human Subjects Protection Training requirement is the Collaborative Institutional Training Initiative (CITI) basic course. ${ }^{11}$

CITI was developed by the University of Miami and covers the topics listed in the middle column of the Figure. CITI is a self-guided module consisting of reading, supplemental resources, and a quiz. An $80 \%$ average on all quizzes must be achieved to pass. This is also the course required by the American Academy of Family Physicians (AAFP) IRB, on which the Academy of Nutrition and Dietetics relies for reviews of research involving human subjects.

\section{COURSE DEVELOPMENT}

CITI was selected as the basis for the RDN-targeted course because of its popularity and because it is the required training for the AAFP IRB. In addition, researchers at the Case Western Reserve University Center for Reducing Health Disparities had already completed substantial work to make the CITI content relevant to individuals new to research as part of their community researcher training program. In their model, trainees attended approximately 4 hours of lecture on the CITI content with additional explanations and context as well as relevant examples to community research. During the training, 96 slides were reviewed and topics mirrored those in the CITI course (middle column of the Figure). Trainees then completed the CITI course and quizzes as usual, but with their preparatory work were able to comprehend the material more quickly and understand the application of research principles and regulatory protections to their work (M. E. Lawless, MA, RN, oral communication, January 2013).

A similar prep course model was selected for the new RDN course, and the community researcher slides were modified based on the expertise of the researchers and their perceptions of what topics were particularly relevant and/or confusing to nutrition and dietetics practitioners and students. For example, to help define research, a section on the difference between standard care, quality improvement, and research was added because RDNs may be more comfortable with the first two concepts and can use this information to contextualize new knowledge about research as defined by the 45 CFR 46 or the Common Rule. $^{12}$ The relationship between research ethics and the dietetics code of ethics ${ }^{13}$ was also emphasized, and more time was spent on records-based research because this is often an easy entry point to research. Dietetics examples were added when possible, such as examples of risks in dietetics research. In addition, the community researcher and IRB/ethics expert on the team modified and improved the content to provide clear and concise explanations of federal regulations and common institutional requirements.

A draft of 116 slides was sent to chairs of the Academy's Ethics Committee and DPBRN Oversight Group and a member of the Research Committee for their review. They were asked to identify where additional dietetics examples could be added, what content was 
missing, and whether any content was overemphasized. Based on these reviews, the content was modified and more examples were added.

Although the training was initially planned to be delivered in person to dietetics interns and students enrolled in Northeast Ohio Accreditation Council for Education in Nutrition and Dietetics programs, no students attended the session; therefore, the training was further modified to fit within a 90-minute webinar. Topics on special populations (eg, children, schools, prisoners) and Internet research were eliminated and content on informed consent was pared down. These topics were covered in new handouts and may be developed into supplementary training modules at a later date. In addition, the material was reorganized into six sections rather than following the CITI module order exactly: defining research and human subjects, history and ethics in research, regulations, risk, privacy, and conflict of interest. Topics covered and their relationship to the CITI course are in the right column of the Figure.

\section{PILOT TEST}

The webinar was held in April 2014 and attendees were able to receive $1 \mathrm{CPE}$ credit. All members of the DPBRN $(n=1,604)$ were invited via e-mail to attend the 90-minute live webinar. The webinar was delivered by three experts and there was time for questions.

To evaluate the new course, webinar attendees were invited to take part in an anonymous online survey. The invitation and survey link were provided at the end of the course and in a follow-up e-mail. The survey included demographic questions, research activity questions based on Byham-Gray's research and evidence-based practice model, ${ }^{14}$ confidence in research ethics questions based on two validated surveys, ${ }^{15,16} 10$ application/comprehension quiz questions, and open-ended questions about the best and worst parts of the webinar and recommendations for modifications. The survey was open for 3 weeks, starting immediately after the webinar. All webinar attendees obtained CPE credit, regardless of survey participation. Respondents to the survey read an informed consent page prior to entering the survey. IRB approval and a waiver of signed consent was obtained from Case Western Reserve University.

Analysis was descriptive only. The investigators sought to identify areas of the course that might need improvement based on lack of confidence on the research ethics-related evaluation question or based on low scores on the application questions. Analysis of the qualitative free text responses was also focused on areas for changes or improvement in the content.

\section{SURVEY FINDINGS}

Seventy-five individuals attended the webinar; $34(45 \%)$ of those completed the survey. Participants were relatively experienced in research and the concepts of research ethics, with $24(73 \%)$ having taken a human subjects protection training course in the past (Table 1).

Respondents were generally confident in completing research ethics-related evaluations, with the mean score greater than 3 (on a 5-point scale where $1=$ strongly not confident and 
$5=$ very confident), except in the area of consenting vulnerable subjects (Table 2). This was the area that had both the lowest mean score, and only one individual selected very confident (2.9\%). Describing the relationship between the Healthy Insurance Portability and Accountability Act (HIPAA) and research was the activity in which respondents felt most confident (mean score 3.9; 20 respondents [59\%] rated themselves at a 4).

Those with experience in research trended toward higher confidence in the research-related decisions, but because of the small sample and sub-sample size, statistical comparison was not conducted.

Scores on the knowledge quiz were generally good; the mean score on the quiz was $84 \%$, with only four individuals (11.8\% of sample) scoring fewer than 8 correct out of 10 . For 7 of 10 questions, more than $80 \%$ of respondents choose the correct answer (Table 3). The three questions that were more frequently missed covered the topics of records-based research, informed consent documentation, and conflict of interest.

Overall, the free-text responses indicated that the material was helpful to those with less experience in research, but that it was repetitive for those who had already completed CITI or were experienced researchers. Individuals appreciated the dietetics-specific examples but requested more of them, and also appreciated the differentiation between quality improvement projects and research. More information about conflict of interest, communitybased research scenarios, and development and implementation of the informed consent process were requested.

\section{ASSESSING THE COURSE}

Responses to the survey suggest that this is a valuable resource and improves knowledge of RDNs in the area of research ethics and protection of human subjects. The use of only a post-test (rather than a pre/post design) limits conclusions about whether the course or prior knowledge was responsible for the quiz scores, but free-text responses suggest that the course did increase learners' knowledge. The sample size was relatively small and had a high level of research experience, which limits the generalizability. This is likely due to selfselection bias as well as the fact that respondents were all recruited from the DPBRN, indicating a higher level of baseline interest in research. In addition, previous surveys have shown that the DPBRN has a higher than predicted representation of educators and researchers compared with Academy members overall. However, DPBRN members are the first target audience for this tool, so the use of this group for pilot testing is valid.

The pilot design did not allow us to test the hypothesis that completing this training helped make the CITI course more relevant and easier. Members who participate in research through the DPBRN and other research overseen by the Academy will still need to complete the CITI training to fulfill the requirements of the AAFP IRB. The goal of this development and testing was not to replace CITI, but rather to provide context for the material. The relatively high level of experience of the survey participants and their positive comments and quiz scores suggest a level of face validity that the correct material is covered. 
We have modified the content based on the suggestions, including changing the format to 1.5 hours and an equal number of CPEs. In addition, descriptive material about the course will emphasize that it is for those new to research and may not be valuable to experienced researchers. Informed consent in special situations has been highlighted, as well as including more information on and the relationship to records-based research. The difference between respondents' high confidence in evaluating the relationship between HIPAA and research but their low scores on the application question related to this topic suggest that more information on this topic is needed. Respondents were likely familiar with the term HIPAA and its application in clinical settings, but need to understand HIPAA and research. We also added material about activities that constitute research misconduct, because this may be a new topic for less-experienced researchers and can help contextualize research activities within a broader ethical framework.

Accompanying handouts were developed as a resource for attendees of the new self-study modules, which are available to Academy members on the DPBRN website. Further evaluation will track whether the availability of this new resource increases the number of individuals able to participate in DPBRN projects. The DPBRN may also explore with the AAFP IRB whether this training could substitute for CITI in Academy-sponsored projects. However, given the multi-institutional nature of DPBRN projects, many clinicians will have to fulfill their own institution's training requirements, such as CITI, which may make the prep course approach more realistic. The Research Ethics for the Registered Dietitian Nutritionist self-study modules will prepare the practitioner, facilitate understanding of the applicability of research regulations, and promote the RDN's participation in research. In addition, this resource may be useful to dietetics educators to meet aspects of the research competencies.

This pilot test suggests that the end-product is useful and informative, and that participants can answer questions showing their ability to apply the material to research situations. Because it is dietetics-specific and assumes a very low baseline knowledge of research, we believe it will be approachable for many nutrition and dietetics practitioners and students who are just beginning research. Other organizations may wish to follow this model of translation of generic academic materials to specialty-and practitioner-specific trainings to enhance member value of research. Paired with other resources for conducting research from the Academy, ${ }^{17}$ this tool can help integrate research into the culture of dietetics, which will help show the evidence for the efficacy of the RDN's services.

\section{Acknowledgments}

\section{FUNDING/SUPPORT}

This publication was made possible by the Clinical and Translational Science Collaborative of Cleveland, UL1TR000439 from the National Center for Advancing Translational Sciences (NCATS) component of the National Institutes of Health (NIH) and NIH roadmap for Medical Research, and NIH P60 grant MD00265.

The authors thank Anne Mathews, PhD, RD, Jerrilynn D. Burrowes, PhD, RD, and Suzy Weems, PhD, RD, CSSD, for reviewing the slides; Carrie King, $\mathrm{PhD}, \mathrm{RD}, \mathrm{CDE}$, for her assistance in locating survey tools; and two members of the DPBRN Oversight Group-Helen Lane, PhD, RD, and Ellen Anderson, MS, RD, LD—for their reviews. The authors appreciate their feedback. 


\section{References}

1. Academy of Nutrition and Dietetics. [Accessed July 2, 2014] HOD backgrounder: Engaging members in research. http://www.eatright.org/WorkArea/linkit.aspx? LinkIdentifier $=$ id\&ItemID $=6442479886 \&$ libID $=6442479863$. Updated 2014

2. Bradley DW, Murphy G, Snetselaar LG, Myers EF, Quails LG. The incremental value of medical nutrition therapy in weight management. Manag Care. 2013; 22(1):40-45. [PubMed: 23373140]

3. Gardner JK, Rall LC, Peterson CA. Lack of multidisciplinary collaboration is a barrier to outcomes research. J Am Diet Assoc. 2002; 102(1):65-71. [PubMed: 11794504]

4. King C, Byham-Gray L, O’Sullivan Maillet J, Scott Parrott J, Splett P, Roberts MM. Dietitians and research: Facilitating involvement: History of dietitian involvement in dietetics research in the U.S. Top Clin Nutr. 2014; 29(3):227-238.

5. National Institutes of Health Office of Extramural Research. [Accessed July 2, 2014] Frequently asked questions: Human subjects research—Requirement for education. http:/grants.nih.gov/grants/ policy/hs_educ_faq.htm\#229. Published December 12, 2013. Updated 2013

6. Anderson EE, Solomon S, Heitman E, et al. Research ethics education for community-engaged research: A review and research agenda. J Empir Res Hum Res Ethics. 2012; 7(2):3-19. [PubMed: 22565579]

7. Morin K, Rakatansky H, Riddick FA Jr, et al. Managing conflicts of interest in the conduct of clinical trials. JAMA. 2002; 287(1):78-84. [PubMed: 11754712]

8. Slawson DL, Clemens LH, Bol L. Research and the clinical dietitian: Perceptions of the research process and preferred routes to obtaining research skills. J Am Diet Assoc. 2000; 100(10):11441148. [PubMed: 11043698]

9. Knowles, MS.; Holton, E.; Swanson, RA. The Adult Learner: The Definitive Classic in Adult Education and Human Resource Development. 7. New York, NY: Taylor \& Francis; 2011.

10. Dougherty C, Burrowes JD, Hand RK. Research experience and barriers to participating in research among members and non-members of the Dietetics Practice Based Research Network (DPBRN) of the Academy of Nutrition and Dietetics. J Acad Nutr Diet. 2014; 114(9):S2:A-66.

11. Collaborative Institutional Training Initiative at the University of Miami. [Accessed July 2, 2014] Mission and history. https://www.citiprogram.org/index.cfm?pageID=30

12. US Department of Health and Human Services. [Accessed July 2, 2014] Code of Federal Regulations: Title 45: Public Welfare: Department of Health and Human Services: Part 46: Protection of Human Subjects. http://www.hhs.gov/ohrp/policy/ohrpregulations.pdf. Revised January 5, 2009

13. American Dietetic Association. American dietetic Association/Commission on Dietetic Registration code of ethics for the profession of dietetics and process for consideration of ethics issues. J Am Diet Assoc. 2009; 109(8):1461-1467. [PubMed: 19642246]

14. Byham-Gray LD, Gilbride JA, Dixon LB, Stage FK. Evidence-based practice: What are dietitians' perceptions, attitudes, and knowledge? J Am Diet Assoc. 2005; 105(10):1574-1581. [PubMed: 16183358]

15. Swenson-Britt E, Berndt A. Development and psychometric testing of the nursing research selfefficacy scale (NURSES). J Nurs Meas. 2013; 21(1):4-22. [PubMed: 23786131]

16. Mullikin EA, Bakken LL, Betz NE. Assessing research self-efficacy in physician-scientists: The clinical research APPraisal inventory. J Career Assess. 2007; 15(3):367-387.

17. Hand RK. Research in nutrition and dietetics-what can the academy do for you? J Acad Nutr Diet. 2014; 114(1):131-135. [PubMed: 24342604] 


\begin{tabular}{|c|c|c|}
\hline Content Area & $\mathrm{CITI}^{\circ}$ Social and Behavioral Research & $\begin{array}{l}\text { Research Ethics for the } \\
\text { Registered Dietitian Nutritionist } \\
\text { Self-Study Modules }\end{array}$ \\
\hline $\begin{array}{l}\text { Introduction to Research/Defining } \\
\text { Research with Human Subjects }\end{array}$ & $\begin{array}{l}\text { Interpretation of definitions of terms } \\
\text { human subject and research for social } \\
\text { and behavioral research }\end{array}$ & $\begin{array}{l}\text { - Dietetics Code of Ethics } \\
\text { - Research vs standard of care } \\
\text { vs quality improvement } \\
\text { - What is a human subject? }\end{array}$ \\
\hline $\begin{array}{l}\text { History of Research Abuse, } \\
\text { Ethics, and Federal Regulations }\end{array}$ & $\begin{array}{l}\text { - History of abuses in research } \\
\text { - Development of federal regulations } \\
\text { from } \mathrm{SBR}^{\mathrm{b}} \text { perspective } \\
\text { - Why ethics are necessary for } \mathrm{HSR}^{\mathrm{c}}\end{array}$ & $\begin{array}{l}\text { - History of abuses in research } \\
\text { Development of federal } \\
\text { regulations in response } \\
\text { to abuse } \\
\text { - Necessity of federal } \\
\text { regulations for HSP } \\
\text { - Who has to follow federal } \\
\text { regulations for HSP? }\end{array}$ \\
\hline Ethical Principles & - Belmont Principles & $\begin{array}{l}\text { - Belmont Principles } \\
\text { - } \text { Dietetics Code of Ethics }\end{array}$ \\
\hline Federal Regulations & $\begin{array}{l}\text { - Overview of federal regulations } \\
\text { - Pertinence to social and behavioral } \\
\text { research } \\
\text { - Requirements for/types of review } \\
\text { necessary for social and behavioral } \\
\text { research }\end{array}$ & $\begin{array}{l}\text { - Overview of } \\
\text { federal regulations }\end{array}$ \\
\hline Institutional Review Boards & $\begin{array}{l}\text { - Composition } \\
\text { - Functions } \\
\text { - Review process } \\
\end{array}$ & - Review process \\
\hline Informed Consent & $\begin{array}{l}\text { - Required and optional elements } \\
\text { - Obtaining informed consent } \\
\text { Waivers of informed consent }\end{array}$ & $\begin{array}{l}\text { - Information, understanding, } \\
\text { and voluntariness } \\
\text { - Required elements } \\
\text { - Obtaining informed consent } \\
\text { - Waivers of informed consent } \\
\text { - Waivers of informed consent } \\
\text { documentation }\end{array}$ \\
\hline Risk/Benefit & $\begin{array}{l}\text { - Identifying risks } \\
\text { - Evaluating risks vs potential } \\
\text { benefits } \\
\text { - Managing risks } \\
\text { - Addressing risks during the } \\
\text { informed consent process }\end{array}$ & $\begin{array}{l}\text { - Severity and types of risks } \\
\text { - Possible protections } \\
\text { andribution of risks } \\
\text { and benfits }\end{array}$ \\
\hline Privacy and Confidentiality & $\begin{array}{l}\text { - Definitions of privacy and } \\
\text { confidentiality } \\
\text { - Private vs public behavior }\end{array}$ & $\begin{array}{l}\text { - Definitions of privacy } \\
\text { and confidentiality }\end{array}$ \\
\hline
\end{tabular}

\begin{tabular}{|c|c|c|}
\hline Content Area & $\mathrm{CITI}^{\mathrm{a}}$ Social and Behavioral Research & $\begin{array}{l}\text { Research Ethics for the } \\
\text { Registered Dietitian Nutritionist } \\
\text { Self-Study Modules }\end{array}$ \\
\hline & $\begin{array}{l}\text { - Procedures for protecting } \\
\text { privacy and confidentiality } \\
\text { controlling access to private } \\
\text { information } \\
\text { - Reporting laws and certificates } \\
\text { of confidentiality } \\
\text { - Exempt research }\end{array}$ & $\begin{array}{l}\text { - How to maintain participants' } \\
\text { privacy and keep research } \\
\text { information confidential } \\
\text { - } \text { HIPAA }^{\mathrm{e}} \text { privacy rule } \\
\text { - Social media }\end{array}$ \\
\hline Vulnerable Populations & (none) & - Concept \\
\hline Research Integrity & (none) & - Conflict of Interest \\
\hline Special Types of Research & (none) & - Records based \\
\hline
\end{tabular}

Figure.

Standard human subjects protections topics and their coverage in the Research Ethics for the

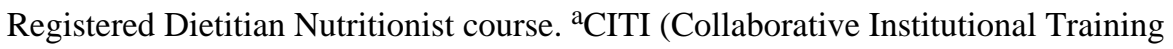
Initiative) Basic Courses in the Protection of Human Research Subjects. Description of all CITI modules: https://www.citiprogram.org/citidocuments/forms/Human\%20Subjects \%20Research\%20(HSR)\%20Catalog.pdf. bSBR=Social and Behavioral

Research. ${ }^{\mathrm{c}} \mathrm{HSR}=$ Human Subjects Research. ${ }^{\mathrm{d}} \mathrm{HSP}=$ Human Subjects

Protection. ${ }^{\text {eHIPAA}=H e a l t h ~ I n s u r a n c e ~ P o r t a b i l i t y ~ a n d ~ A c c o u n t a b i l i t y ~ A c t . ~ A d a p t e d ~ w i t h ~}$ permission from CIRTification: Community Involvement in Research Training, developed by Emily E. Anderson and available at www.go.uic.edu/CIRTification. 


\section{Table 1}

Demographic characteristics and previous experience in research as reported by Dietetics Practice Based Research Network members who attended a Research Ethics webinar and completed a post-webinar survey to determine the value of the training ${ }^{a}$

\begin{tabular}{|c|c|c|}
\hline \multicolumn{3}{|l|}{ Demographic characteristics } \\
\hline \multirow{3}{*}{$\begin{array}{l}\text { Years in dietetics } \\
\text { Credentials/education }(n=33)\end{array}$} & \multicolumn{2}{|c|}{$\underline{\text { mean } \pm \text { standard deviation }}$} \\
\hline & \multicolumn{2}{|c|}{$24 \pm 13.3$} \\
\hline & $n$ & $\%$ \\
\hline Registered dietitian nutritionist & 32 & 94.0 \\
\hline State license & 20 & 59.0 \\
\hline Master's & 11 & 32.0 \\
\hline Doctorate & 5 & 15.0 \\
\hline Specialty credential $\left(\mathrm{CDE}^{b}, \mathrm{CSO}^{c}, \mathrm{CNSC}^{d}\right)$ & 9 & 26.0 \\
\hline \multicolumn{3}{|l|}{ Practice area $(n=34)$} \\
\hline Clinical nutrition & 9 & 26.5 \\
\hline Education & 5 & 14.7 \\
\hline Research & 5 & 14.7 \\
\hline Diabetes care & 3 & 8.8 \\
\hline Food and nutrition management & 2 & 5.9 \\
\hline Long-term care & 2 & 5.9 \\
\hline Pediatrics & 2 & 5.9 \\
\hline Renal nutrition & 2 & 5.9 \\
\hline Communications/publications & 1 & 2.9 \\
\hline Community nutrition & 1 & 2.9 \\
\hline Consultation and private practice & 1 & 2.9 \\
\hline Oncology & 1 & 2.9 \\
\hline \multicolumn{3}{|l|}{ Previous exposure to $\mathrm{HSPT}^{e}(\mathrm{n}=33)$} \\
\hline CITI $f$ training & 16 & 48.5 \\
\hline $\mathrm{NIH}^{g}$ Human Subjects Training & 7 & 21.2 \\
\hline Another HSPT training & 1 & 3.0 \\
\hline None & 9 & 27.3 \\
\hline \multicolumn{3}{|l|}{ Past participation in research activities $h$} \\
\hline Searching the literature (on Pubmed or another database) & 30 & 93.8 \\
\hline Critically reading the literature & 29 & 90.6 \\
\hline Collecting data & 28 & 87.5 \\
\hline $\mathrm{IRB}^{i}$ approval process & 22 & 68.8 \\
\hline Developing a research question & 20 & 62.5 \\
\hline Developing a research protocol & 19 & 59.4 \\
\hline Analyzing data & 19 & 59.4 \\
\hline Consenting subjects & 17 & 53.1 \\
\hline Publishing or presenting data & 16 & 50.0 \\
\hline
\end{tabular}


${ }^{a}$ Responses are presented as a percent of those who answered or mean and standard deviation, as appropriate.

${ }^{b} \mathrm{CDE}=$ certified diabetes educator.

${ }^{c} \mathrm{CSO}=$ certified specialist in oncology nutrition.

$d_{\mathrm{CNSC}=\text { certified nutrition support clinician. }}$

${ }^{e} \mathrm{HSPT}=$ human subjects protection training.

$f_{\text {CITI=Collaborative Institutional Training Initiative. }}$

$g_{\mathrm{NIH}=\text { National Institutes of Health. }}$

$h_{\mathrm{n}=32 ; 2}$ either skipped or were never involved in any activities.

${ }_{\text {IRB }}=$ Institutional Review Board. 


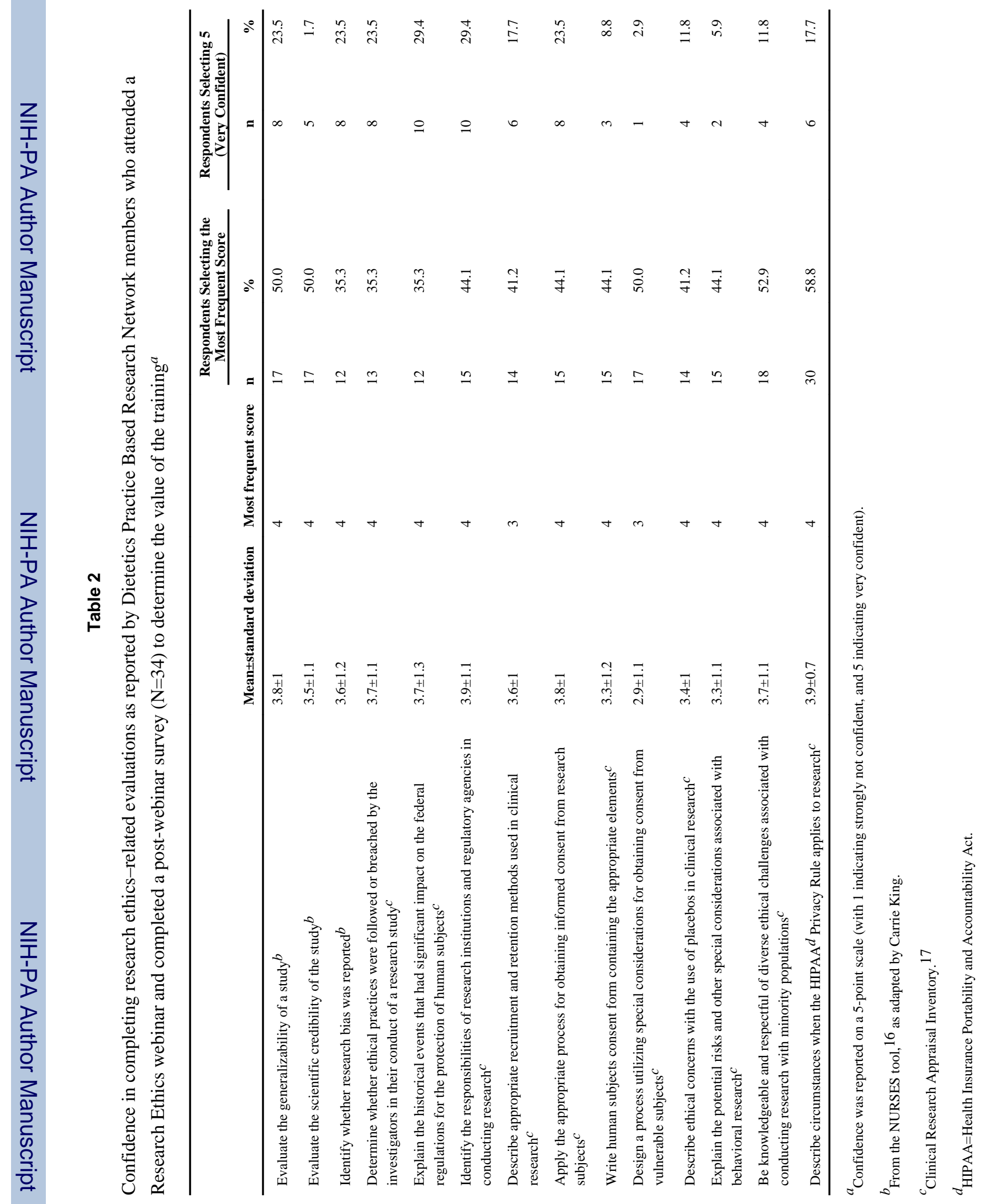




\section{Table 3}

Scores on the knowledge quiz completed by Dietetics Practice Based Research Network members (N=34) who attended a research ethics webinar and completed a post-webinar survey to determine the value of the training

\begin{tabular}{llr}
\hline Question & Respondents with Correct Answer \\
\cline { 2 - 3 } Which of the following things would the Institutional Review Board (IRB) need to approve? & $\mathbf{n}$ & \% \\
\hline Which of the following items are required to be covered in the informed consent process? & 34 & 100 \\
Which of the following describes the purpose of an IRB? & 34 & 100 \\
Which of the following is a risk in dietetics that must be disclosed to study participants? & 31 & 100 \\
Which of the following does NOT include a human subject according to federal definitions? & 27 & 94 \\
Which of the following items would the IRB NOT need to review? & 26 & 81 \\
Which of the following is an example of research, as defined by the federal regulations? & 24 & 81 \\
Which of the following is true about obtaining informed consent from research subjects? & 21 \\
Which of the following is NOT a conflict of interest and does not need to be disclosed/acknowledged? & 19 & 62 \\
What is true of a record? & 56 \\
\hline
\end{tabular}

